\title{
Developments Regarding Dysfunctional Voiding and Urinary Tract Infections in Children
}

\author{
Yusuf Kibar and Faysal Gok \\ Additional information is available at the end of the chapter
}

\section{Introduction}

Urinary tract infection (UTI) is the most commonly diagnosed bacterial infections of childhood, and have a significant healthcare impact. Renal parenchymal infection and scarring are well-established complications of UTI in children and can lead to renal insufficiency, hypertension and renal failure. Although frequently encountered and well researched, diagnosis and management of UTI continue to be a controversial issue with many challenges for the clinician [1].

Dysfunctional voiding (DV) imposes a considerable social, developmental and physical burden on children and their families. Children that suffer from DV generally present with complaints of UTI, incontinence, constipation and voiding symptoms such as urinary urgency and frequency. Vesicoureteral reflux (VUR) may also be present in some children with more severe DV, possibly resulting in hydronephrosis, pyelonephritis and even secondary chronic renal insufficiency [2].

The true estimate of DV in the general population is not known. Reported population estimates of DV are based on questionable methodology. A wide variation from $4.2-46.4 \%$ has been reported depending on the definition used and the methodology adopted $[3,4]$. It is probable that these figures represent a gross overestimate of the actual prevalence. In tertiary care centres, DV constitutes up to $40 \%$ of referrals in the Paediatric Urology department $[2,5]$.

This chapter will focus on the epidemiology, diagnosis and management of DV and UTI in neurologically and anatomically normal children. The discussion will highlight recent developments and research in the clinical approach of DV and UTI. 


\section{Definitions and classification}

Children with significant lower urinary tract symptoms without associated neurological or anatomical abnormalities are considered to have non-neurogenic (idiopathic) lower urinary tract dysfunction (LUTD). It represents a disturbance of the lower urinary tract dynamics affecting urine storage or emptying and can simply be categorized into two types in children $[2,6]$ :

1. Problems related to the filling (storage) phase include overactive bladder (OAB) syndrome, functional urinary incontinence, and giggle incontinence.

2. Disturbances of the emptying (voiding) phase include dysfunctional voiding (DV), lazy bladder syndrome, Hinman syndrome, and post-void dribbling.

Confusion can occur in identifying these syndromes as they may exist as a single entity or in combination and can be progressive.

Overactive bladder $(\mathrm{OAB})$ syndrome, which is the most common pattern in children with LUTD, includes involuntary detrusor contractions and urethral instability. In children, OAB is the result of sudden and overwhelming urge to void that requires immediate urethral compression by the pelvic floor or by external manoeuvres such as the Vincent curtsy. This syndrome may also result in constipation from chronic pelvic musculature contraction [2]. $\mathrm{OAB}$ is thought to be due to a delay in acquisition of cortical inhibition over uninhibited detrusor contractions in the course of achieving the mature voiding pattern of adulthood. Abnormal overactivity of the pelvic floor musculature during voiding, instead of a complete relaxation, results in interrupted micturation [7]. The diagnosis of OAB syndrome can be made on examining the history of incontinence related to urgency, and does not require urodynamic evidence of uninhibited detrusor activity.

Functional urinary incontinence is the failure of the sphincteric mechanism to maintain continence in anatomically normal children. True stress urinary incontinence in which there is an anatomic insufficiency of the sphincteric mechanism to hold urine in transmission of abdominal pressures to the bladder is rare in children [2].

Giggle incontinence is almost exclusively seen in girls and is characterized by large-volume voiding that can occur with laughing. These patients have no voiding symptoms between episodes and no other episodes of incontinence. The diagnosis is based on history alone and, unless there is a history of UTI, no further evaluation is needed. Although the aetiology is not clear, this may be a centrally mediated disorder similar to another disorder, cataplexy, in which an emotional event causes muscle hypotonia. Accordingly, there is evidence that the central nervous system stimulant, methylphenidate, may be effective in prevention of these events [8].

Dysfunctional voiding is an abnormal contraction of the voluntary sphincter and pelvic floor during voiding that is thought to be an acquired disorder that may progress to complete loss of bladder function [9]. Voiding dysfunction has been used and is no longer an acceptable term. This term describes malfunction during the voiding phase only. 
It says nothing about the storage phase. The term cannot be applied unless repeat uroflow measurements show curves with a staccato pattern or unless verified by invasive urodynamic investigation [10]. Due to the abnormal contraction of the pelvic floor (pelvic floor dysfunction), constipation is common in these children. Dysfunctional elimination syndrome (DES) is often used to describe this disorder because this term accounts for the link between the difficulty in voiding and defecation caused by the abnormal contraction of the pelvic floor [3]. In recent studies, the rate of OAB in children with LUTD was reported variously as $58 \%$ and $71 \%$. It has been suggested that the rate of DV is lower than that of $\mathrm{OAB}[11,12]$.

Lazy bladder syndrome or myogenic failure is the loss of detrusor activity that requires the Valsalva maneuver to fully empty the bladder [2]. This condition is seen in about 7\% of all dysfunctional voiders and typically occurs in females with a ratio of 5:1 to males [8]. Longterm fractionated voiding is thought to be the cause of this syndrome in which long voiding times result in loss of the normal detrusor function. Voiding is accomplished by increasing abdominal pressure to empty. Infrequent voids, large-volume post-void residuals with overflow incontinence, and UTIs are the prevalent symptoms and signs. As a rule, urodynamic evaluation demonstrates a large-capacity, very compliant bladder; however, some of these patients may also demonstrate a degree of detrusor overactivity [8].

Hinman syndrome or nonneurogenic neurogenic bladder (NNNB) is often interchanged with occult neuropathic bladder and represents full decompensation of the voiding mechanism. Children will present with day and night-time incontinence, chronic UTIs, and chronic constipation. Urodynamic studies will often show uninhibited detrusor activity during filling, high filling pressures, large post-void residual (PVR) volumes, and abnormal activity of the pelvic floor musculature during voiding. Imaging studies results are frequently abnormal with hydroureteronephrosis secondary to VUR being common [2].

Post-void dribbling is a disorder in which incontinence of urine occurs immediately after micturition. This syndrome is more common in female patients and is thought to be secondary to retained urine in the vagina that leaks after standing. Even though it is more likely to occur in obese girls it can also happen frequently in girls who are thin. This pattern can be seen on voiding cystourethrography. This can produce irritation of the labia, dysuria as the urine passes over the irritated skin, a reduced desire to void, incomplete emptying, and eventually recurrent UTI with its consequent changes in bladder function that further aggravate the clinical picture. Although these symptoms usually resolve with age and normal growth, the child may improve the symptoms more abruptly by facing backwards on the toilet with her body tilted forward and her legs straddling the toilet, or by manually spreading the labia majora with fingers as she voids [8].

\section{Aetiology and pathogenesis}

The aetiology of DV in otherwise healthy, neurologically intact children remains a matter of debate. In the absence of any neurologic or anatomic findings, the voiding patterns in DV 
are often believed to originate from behavioural issues. These behavioural traits may evolve from adverse events that occur around or after the time of toilet training and/or personal stresses [13]. Severe emotional stressors, such as sexual abuse mainly in girls, has been associated with DV, and should be considered in a child, especially a girl, who presents with new onset DV and no other identifiable etiologic factor $[4,5]$.

Detrusor overactivity as a component of DV may represent a persistence of the normal infant voiding pattern after toilet training. It may be that a mild delay in the maturation of the central nervous system disrupts the ability of these children to learn true voluntary control over the micturition reflex $[5,14]$. An alternative theory to the development of the urge syndrome hypothesizes that detrusor overactivity is caused by the transient obstruction that occurs with DV [15]. In support of the belief that the roots of DV may be grounded in behavioural issues or central nervous system developmental delays, an association has been demonstrated between DV and attention deficit hyperactivity disorder (ADHD). Higher rates of enuresis, urinary incontinence, constipation, and other voiding symptoms have been described in children with ADHD $[16,17]$.

As a result of studies of DV diagnosed in infancy, a congenital or genetic component to the disorder has also been postulated. Small series of infants with signs and symptoms consistent with NNNB syndromes have been reported [18, 19]. Furthermore, DV has been linked to the Ochoa syndrome, a genetic disorder with an autosomal recessive inheritance pattern. The gene locus at chromosome 10q23-q24 is identified as the defective gene in Ochoa syndrome. It is postulated to be the possible gene locus of the NNNB described by Hinman and Allan [20]. This information casts doubt on the commonly held belief that disturbance of behaviour is the sole cause of NNNB because these findings are present at or near the time of birth.

At least some patients with DV represent occult neurogenic problems that will manifest provided these patients are followed longitudinally [21]. In all individuals with unexplained severe DV, search for an unidentified neurological lesion must be made. A subtle neurological insult could present as DV. Such lesions may or may not be detectable with current imaging technologies. Routine magnetic resonance imaging in children with lower urinary tract problems without overt neurological signs and symptoms has a low yield of $7.5 \%$ but this may be improved by targeting children with abnormal cutaneous findings [22]. Tethered cord syndrome may be identified in some patients with subtle neurological signs and symptoms. Classical tethered cord has been diagnosed on the basis of pathologically elongated conus or conus that lies below the L2 level. However, anecdotal successful outcomes following surgical division of the filum in children with apparently normally located cords suggest that the cord may sometimes be abnormally stretched without being at an abnormal location [23]. Such subtle lesions might also explain the occasional presentation in infancy when the problem has its onset before toilet training has commenced [19]. Surgical division of the filum terminale in such patients is controversial but may yield improvements in bladder dysfunction [24].

Another possible indirect evidence for an unidentified neurological lesion in these patients is the association of a peculiar facial expression in some children with DV [25]. 
The association of facial expression with bladder function in this "Urofacial Syndrome" has been explained by the proximity of the cortical centres for the bladder and facial expression in the brain. Presumably, this makes an association of abnormality between the two centres more likely.

A higher than expected association of idiopathic hypercalciuria, ranging from $21-30 \%$, has been noted in children with DV syndromes. However, almost all responded to behavioural therapy, dietary modifications and anticholinergics and treatment specifically directed at hypercalciuria were needed in only two percent [26]. The reason for an association between hypercalciuria and DV remains unclear. The authors postulated that calcium microcrystallization may cause injury to the urothelium and this could trigger a variety of urinary symptoms including DV.

It is probable that the entity DV is not homogenous and that there are several distinct aetiologies that can lead to it. The end result is one of a dyssynergic sphincteric activity in the absence of a clearly defined neurological reason.

\section{Association of LUTD with UTI and VUR}

There is not sufficient reported data on the relationship between the type of LUTD with UTI and VUR. The earliest studies of LUTD mostly dealt with either OAB or DV. This is a somewhat artificial distinction, as these conditions are often combined and sometimes difficult to separate. For that reasons this association will be presented in LUTD children as a whole.

The association between LUTD and UTI has been established, though the causal relationship is not clear. Recurrent UTI has been shown in any studies to be higher in VUR patients with LUTD than in those without such dysfunction $[3,27,28]$. It has been demonstrated that adequate management of LUTD not only decreases the rate of UTI but also increases resolution of the VUR [27, 29]. Traditionally, recurrent UTI and pyelonephritis have been recognized as potential causes of permanent renal damage [30]. Current opinion is that VUR alone is not sufficient to cause UTI or renal damage. Holland et al. reported that girls with primary VUR followed up for 10 years, with no recurrent UTI, did not develop renal scars [31]. Linshaw showed that VUR does not threaten the kidney as long as UTI is promptly treated [32]. The results of these studies suggest that the association between VUR and UTI is necessary for renal damage to occur, mainly in situations of low detrusor pressure. However, VUR may predispose invasion of the renal parenchyma by bacteria. It has been reported that LUTD is an important risk factor for VUR and renal damage [33]. In addition, current studies have showed that increased intravesical pressure associated with LUTD is a primary factor for inducing reflux and renal damage $[12,34]$. In patients who had UTI the presence of reflux increased the rate of renal damage [12].

VUR in LUTD is theorized to be not the result of a short mucosal tunnel, but to be the consequence of the high filling and voiding pressures. In patients with LUTD, uninhibited detrusor contractions and voluntary constriction of the sphincter, causing a functional 
obstruction, increase the intravesical pressure. Increased intravesical pressure can promote VUR through a possible marginal competence in the valve mechanism [34, 35]. Recent studies have shown that the prevalence of VUR among children with idiopathic LUTD is between $14 \%$ and $46 \%$ [11, 12]. Some reports have emphasized bilateral reflux associated with LUTD $[12,36]$.

Van Gool et al. addressed the relationship between DV and reflux for the first time with a retrospective questionnaire in 1992 [37]. The prevalence of uncoordination between the detrusor and urethral sphincter approached $18 \%$ and included voiding pattern abnormalities such as urge syndrome, staccato voiding, fractionated and incomplete voiding, and voiding postponement. They also found that, in those children who had spontaneous resolution of their VUR, there was a lower prevalence of DV.

It is important to carefully assess all children with reflux for subtle signs of DV. Children with DV are more likely to have recurrent UTIs, have mild bilateral reflux with less spontaneous resolution, and are less likely to have success with surgical management. The treatment of DV in such children can improve the chances of spontaneous resolution of the reflux and may also reduce recurrent urinary infection. Koff et al. [3] reported on their series of children with VUR, who either resolved spontaneously or were surgically treated, and found that DES was observed in $43 \%$ of children with primary VUR and in $77 \%$ of a subset of these children who had breakthrough UTI. The presence of DES patterns was associated with a longer time for spontaneous resolution of low-grade reflux and with unsuccessful surgical outcomes. Of children in the surgically treated group, only those with DES developed recurrent and/or contralateral reflux. Children with untreated DV undergoing ureteral re-implantation may be at a higher risk for developing recurrent reflux or a new bladder diverticulum [38].

Contrary to these results, Chen and colleagues reported that VUR and UTI are not independent of DV [39]. Their findings are new observations contradicting the previous belief that both UTI and VUR are independently associated with DES. Chen et al. performed a multivariate analysis on 2759 paediatric urology patients, further examining the relationship between DES, VUR, and UTI. Their data demonstrated a higher rate of DES in girls than in boys: $43.7 \%$ compared with $23.8 \%$. This group also found that there was no difference in the presence of DES in patients with unilateral and bilateral VUR. Surprisingly, they observed no association of VUR or UTI individually with DES but rather DES was only noted when both of these issues were present. Although this large-scale multivariate analysis is a more statistically powerful study than previous smaller retrospective analyses, the data could be potentially skewed in that all of the patients were recruited from a paediatric urology population, which is not representative of the general paediatric population. Patients with known reflux could potentially be protected from DES by prophylactic antibiotics or continued clinical follow-up in a specialty setting. On the other hand, it is suggested that there may be two types of reflux: one that is primary or congenital in nature and another that is secondary and in part due to DES and UTI. This study is in line with the neuroplastic theory that postulates that hypertrophy of the bladder and bowel musculature is caused by trophic factors released during pelvic floor hyperactivity secondary to central nervous disturbances [40]. Hy- 
pertrophy can lead to an increase in risk factors that predispose the urinary tract to more UTIs and more severe VUR including anatomic bladder abnormalities, constipation, increased residual urine, higher voiding pressures, and increased urethral bacteria colonization secondary to turbulent flow [41,42]. Turbulent flow is of particular importance as eddy currents formed by nonlaminar flow leads to reflux of periurethral bacteria to the proximal urethra and bladder (milk back phenomenon), causing recurrent infections.

The pelvic floor musculature is closely related to bowel and bladder. Isolated contraction of the pelvic floor musculature was found to lead to spontaneous contraction of the bladder. The cycle of pelvic floor dysfunction contributing to recurrent UTIs and VUR can cause worsening bladder and bowel symptoms, and increased pelvic floor dysfunction with functional obstruction. Eventually this can lead to a hypertrophied, small-capacity bladder with highpressure voiding that will lead to renal damage. The integral relationship between the pelvic floor activity with UTIs and VUR can be used as a model for developing treatment strategies in affected children to address the cognitive and behavioural aspects of DV and prevent irreversible damage to the upper urinary tract [40].

\section{Diagnosis and evaluation}

Clinical symptoms may vary from mild incontinence to severe disorders with endpoints of irreversible bladder dysfunction with VUR, UTI and resulting nephropathy [8]. Children with DV voiding often present with urinary incontinence both during the day as well as at night. They may have urinary frequency, urgency, urge incontinence or nocturnal enuresis. Such storage symptoms may result from associated detrusor overactivity, urinary infection or reduced bladder capacity consequent to large residual urine and may be aggravated by constipation or behavioural disorders. A distinctive facial expression may be noted in some of these patients [8].

Diagnosis relies heavily on a good history and physical examination, but also includes radiologic and urodynamic evaluation. The history should be directed towards the identification of children with neurologic or anatomic causes of their symptoms, and then distinguish between which form or pattern of voiding dysfunction is present. Components of this history include maternal medical issues, perinatal history, developmental milestones, scholastic performance, behavioural history, specifics around toilet training, patterns of voiding and bowel movements, history of UTI, and family history of voiding dysfunction. The use of a 3-day voiding diary is often helpful to identify the frequency of voiding, voided volumes, and timing of incontinent episodes [9].

Clinical examination must include an assessment of higher mental functions and their ageappropriateness and basic neurological evaluation. On physical examination, attention should be paid to the back and lower spine for cutaneous manifestations of an occult spinal dysraphism and/or sacral agenesis. Neurologic examination should include assessment of lower extremity function, rectal tone, perineal/anal sensation, and intactness of bulbocaver- 
nosus reflex. The external genitalia should also be examined. Bowel function should be evaluated in detail.

Further evaluation of the child with DV continues with a urinalysis and urine culture. The scout film, or plain film of the abdomen (KUB), can be used to assess the spine and sacrum, and for evidence of constipation.

A renal and bladder ultrasonography with a pre-void and post-void image should be obtained to assess for evidence of obstructive uropathy, an ureterocele, bladder wall thickness, and residual urine volume. Studies in healthy infants and toddlers have shown that they do not empty the bladder completely every time but they do so at least once during a 4-hour observation period. In older children, a consistent residual of $>20 \mathrm{ml}$ is considered abnormal [29].

The diagnosis of DV in children hinges upon the repeated demonstration of a staccato pattern on uroflowmetry testing. The normal uroflow pattern is a bell-shaped curve with a smooth up-slope and down-slope. OAB may produce an explosive voiding contraction that appears in the flow measurement as a high amplitude curve of short duration, that is, a tower-shaped curve. A child with organic outlet tract obstruction often has low amplitude and rather even flow curve, that is, a plateau-shaped curve. Finally, in case of an underactive or acontractile detrusor when contraction of the abdominal muscles creates the main force for bladder evacuation, the flow curve usually shows discrete peaks corresponding to each strain, separated by segments with zero flow, namely, an interrupted or fractionated flow curve. The staccato pattern of voiding has been considered classical of DV. Sphincter overactivity during voiding is seen as sharp peaks and troughs in the flow curve, which is as an irregular or staccato flow curve [10] (Figure 1). To label flow as staccato, the fluctuations should be more than the square root of the maximum flow rate. When combined with needle or surface EMG, increased striated urethral sphincter-pelvic floor complex activity can be noted [9]. Less invasive uroflowmetry, perineal electromyography, and PVR comprise the preferred modality at our institution for screening and monitoring response to treatment. Before flow study, bladder ultrasonography is used to ensure adequate volume and exclude patients with overdistention of the bladder. Overdistention of the bladder can obscure results, causing an artificial increase in PVR volumes in normal children [43].

There have been efforts to standardize scoring systems in the evaluation of children with DV. These scoring systems would be beneficial in classifying the type and severity of DV to determine necessary treatment modalities. Farhat et al. introduced the Dysfunctional Voiding Scoring System (DVSS) by comparing the scores of the children aged 3-10 years with age-matched controls across 10 questions related to urinary incontinence, voiding habits, urgency, posturing, bowel habits and stressful life conditions [44]. Nine of these questions are scored between 0 and 3 depending on whether the problem is noted almost never (0), less than half the time (1), about half the time (2) or almost every time (3). The last question is addressed to the parents to identify a stress situation in the family. The authors derived cutoff values of 6 and 9 for girls and boys respectively for making a diagnosis of DV. A small prospective cohort was analyzed by Upadhyay and colleagues to determine the validity of the DVSS in children with reflux. A positive correlation between symptom score improvement and resolution of VUR was found [45]. Another scoring system is the "Dysfunctional 
voiding and incontinence scoring system" and designed by Akbal et al. They reported that the children with a score of 8.5 or greater had voiding abnormalities with $90 \%$ sensitivity and $90 \%$ specificity [46]. The last one was devised by Afshar et al, which was a 14-item 5point Likert scale questionnaire for children with dysfunctional elimination with a cut-off score of 11 [47]. This questionnaire was valid and reliable for diagnosing dysfunctional elimination syndrome. The validity of these scoring systems has not yet been evaluated in large prospective trials.

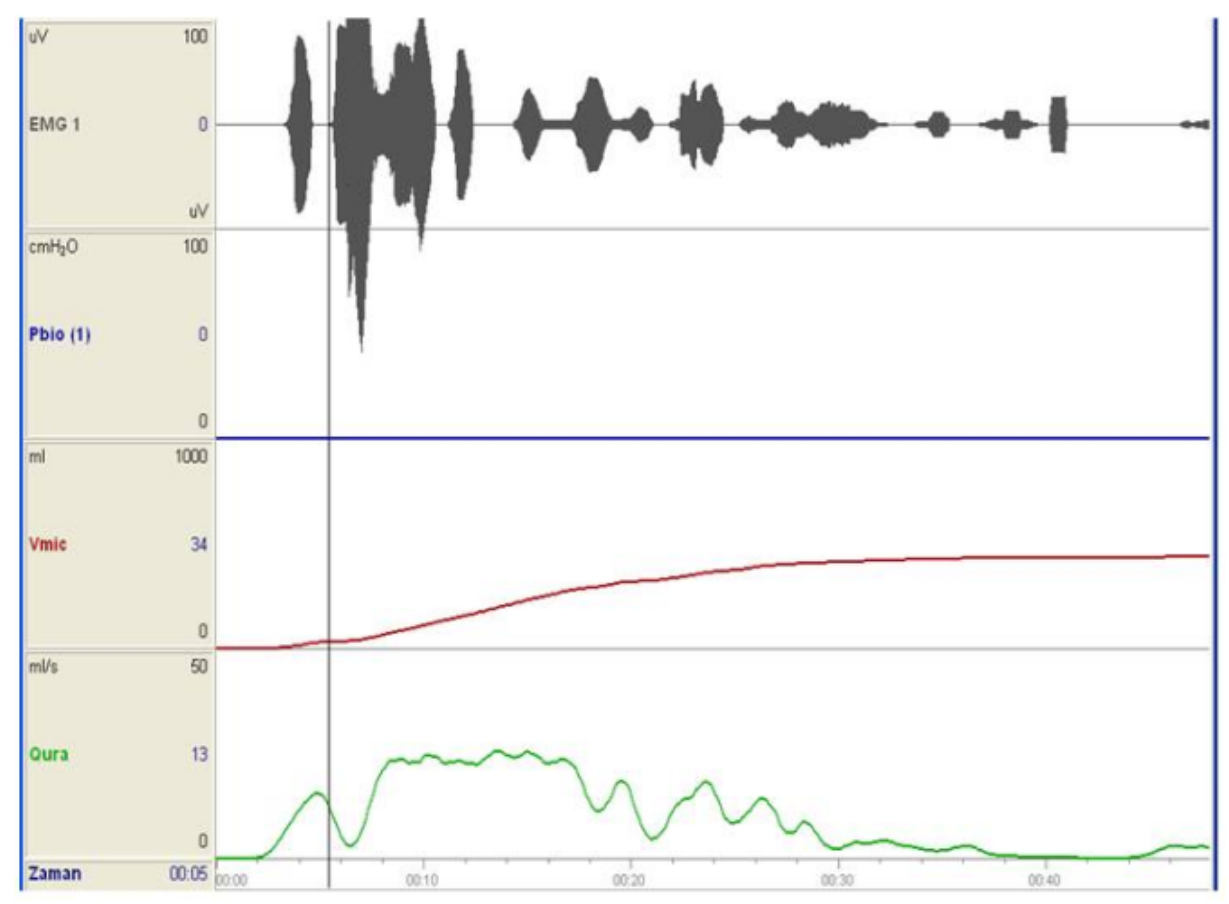

Figure 1. Example of a child with staccato flow and high EMG activity on Uroflow-EMG.

Perineal USG has been used in women with DV to assess sphincter volume [48]. Perineal USG can also be used to evaluate paradoxical pelvic floor movement which may often be seen in children with DV [49]. Abdominal USG has also been used for chronic constipation in children with DV. Rectal diameter greater than $3.5 \mathrm{~cm}$ signifies constipation [50].

Children with DV often show abnormalities on voiding cystourethrogram (VCUG). A VCUG may demonstrate VUR, bladder trabeculation, a diverticulum, a large bladder capacity, or a large post-void residual. Girls may exhibit the spinning top urethra during voiding, which results from dilation of the posterior urethra secondary to detrusor-sphincter uncoordination during voiding [51] (Figure 2). Dilatation of the prostatic urethra may be observed in boys. VCUG should be performed when there is a history of recurrent UTI or a 
febrile UTI, thickened bladder wall on ultrasound, children older than 5 years with day and nighttime incontinence, or children at puberty with persistent enuresis.

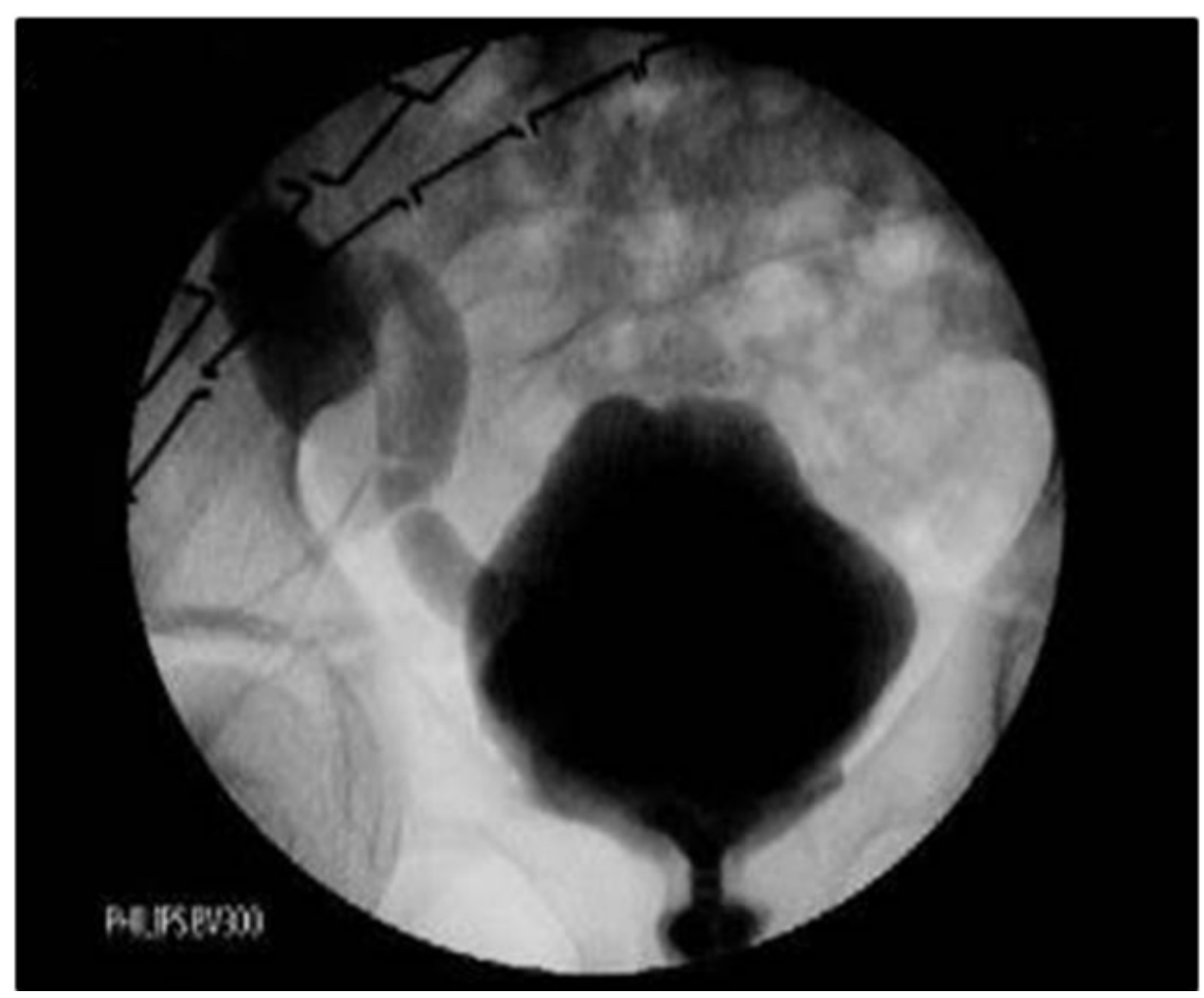

Figure 2. A 6-year old female child with spinning top urethra and right grade 4 VUR on VCUG.

In patients with suspicion of anatomical abnormalities of the lower urinary tract, a diagnostic cystoscopy may be performed. Routine diagnostic cystoscopy is not recommended [52].

Urodynamic evaluation remains an uncomfortable test for children. Cooperation of the child and the narrow size of the urethra are the major hurdles. A relaxed child-friendly environment and patience on the part of the technician are paramount. Full urodynamic studies are considered invasive and should be reserved for children with neurogenic bladder dysfunction, severe DV, myogenic failure, or symptoms that do not improve with therapy $[8,52]$. Urodynamic criteria for DV include too large or small bladder capacity, poor bladder compliance, detrusor overactivity or premature contractions, an unsustained voiding contraction, excessive voiding pressure, an intermittent uroflow pattern, or elevated residual urine. 


\section{Treatment of DV}

Urotherapy is the nonsurgical, nonpharmacologic treatment of lower urinary tract function and can be defined as a bladder re-education or rehabilitation program aiming at correction of filling and voiding difficulties. Standard urotherapy is a combination of informing the child and the family about the normal lower urinary tract function and what is abnormal in the patient's voiding and correcting the abnormal voiding habits, lifestyle with regard to fluid intake and diet.

In the setting of discomfort with voiding or dysuria, all efforts should be made to eliminate any dietary irritants, such as caffeine, carbonated beverages, citrus juices, and chocolate. Furthermore, skin care should be initiated in children with eroded or irritated perineal areas from incontinence.

Education emphasizing timed voiding, fluid management, and pelvic floor exercises are key components of the initial management for DV. In addition, education concerning proper posture during voiding should be emphasized to minimize abdominal musculature straining. Proper sitting technique with buttock and foot support and comfortable hip position is necessary to enable voiding without recruitment of the abdominal muscles [53, 54]. Hygiene education is also important to limit local skin inflammation that may contribute to holding maneuvers and DV. In this way, coordinated voiding with a relaxed pelvic floor can be facilitated at the initiation of management.

Treatment of constipation is also important component of the initial management for DV [55]. Fecal impaction must be managed prior to maintenance therapy. For this purpose laxatives, stool softeners, and enemas is recommended. Maintenance with balanced diet, fibre supplementation, and oral medications such as mineral oil, polyethylene glycol and lactulose are recommended to maintain a goal of one bulky bowel movement a day. Treatment of constipation alone has been shown to resolve lower urinary tract abnormalities. Enuresis resolved in $63 \%$ and daytime incontinence in $89 \%$ of patients presenting with constipation and incontinence in one study [56]. In the same study, resolution of constipation also resolved recurrent UTIs.

Biofeedback therapy is the next line of treatment after conservative approaches have been initiated. Biofeedback is a specific treatment modality that aims to retrain the patient's voiding with the assistance of a computer game. Biofeedback has been used in children as young as four years of age [57]. There is no standard protocol for the correct teaching of biofeedback, but in general there are 2 methods. Real-time uroflowmetry allows the patient to view the urine flow rate that in turn can be used to teach the child to relax his/her pelvic floor musculature with voiding. This method is recommended in children with pelvic floor hyperactivity and no OAB symptoms. Sphincter or pelvic floor electromyography can also be used to teach patients how to voluntarily control their pelvic floor musculature during voiding and thus reduce or prevent detrusor-sphincter incoordination. The advantage in using this method lies in its ability to teach a guarding reflex in addition to the relaxation of the pelvic floor during voiding. 
Improvement in incontinence, UTIs, VUR, and constipation with biofeedback therapy is well documented in the literature. Upwards of $80 \%$ children will experience improvement marked by a reduction in incontinence and recurrent urinary infection [58] (Figure 3). Factors that have been found to improve efficacy of biofeedback include compliance, normal bladder capacity, number of sessions, and use of animation. Independent risk factors to predict failure identified by Herndon and colleagues are small bladder capacity and compliance to therapy [40]. Results appear durable at three years and the treatment also seems to help those children in whom urotherapy has failed [59]. The inclusion of biofeedback in urotherapy is more likely to lead to an improvement in residual urine [60].

For patients who fail to respond to the above conservative measures, medical therapy is often helpful. Anticholinergic agents serve to decrease detrusor overactivity and increase functional bladder capacity in patients with urge syndrome or a detrusor overactivity. Anticholinergics have been shown to provide effective long-term management of detrusor overactivity and may also contribute to a quicker resolution of VUR in the setting of DV [61, 62].

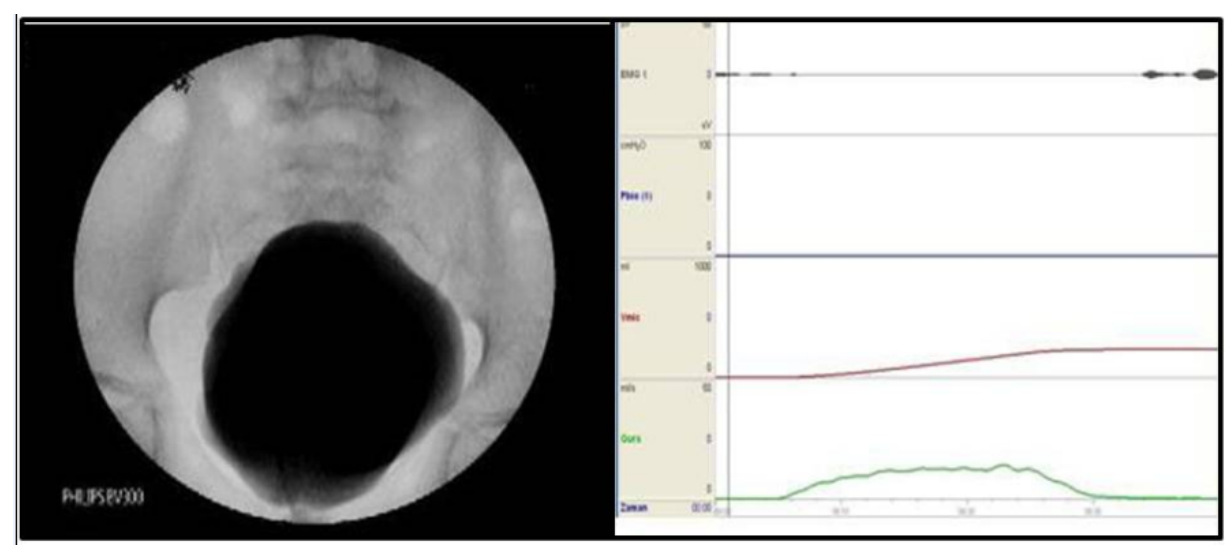

Figure 3. The results of the biofeedback after 4 sessions of treatment in the same child; the appearance of urethra normalized, right grade 4 VUR disappeared on VCUG, and flow curve and EMG activity became normal on Uroflow-EMG.

For patients with small bladder capacity and low PVR in which DV did not improve with 3 sessions of biofeedback, oxybutynin is effective. For children with small capacity bladders and high PVR, a full biofeedback session is often necessary to isolate pelvic floor muscles and lower PVR before initiation of anticholinergics. About $87 \%$ of these patients with smallcapacity bladders who do not improve with biofeedback will improve with the addition of anticholinergics [40].

Clean intermittent catheterization (CIC) has been shown to be useful in children with high PVR volumes or myogenic failure that do not improve with standard therapy. This therapeutic approach has become routine in many patients with DV of various aetiologies. Pohl et al. [63] described their experience with using CIC in the treatment of dysfunctional void- 
ing with a large post-void residual urine volume. It proved to be well tolerated and allowed patients to rapidly attain continence and eliminate recurrent UTI by achieving more effective bladder emptying.

Alpha-adrenergic blockade of receptors at the bladder neck and urethra results in relaxation of smooth muscle and theoretically enables more complete bladder emptying. Although the results have been somewhat mixed, several studies have shown efficacy in reducing subjective symptoms and improving objective urinary parameters in children with DV and increased PVR [64, 65]. Dramatic improvement in flow, initiation of voiding, and PVR was documented in one study by Donohoe and colleagues [66]. All children that met the criteria of primary bladder neck dysfunction (low flow rate, low EMG activity, and delayed initiation of voiding) improved with alpha-blocker therapy and those that discontinued therapy returned to baseline symptoms.

The transurethral injection of botulinum toxin into the striated urethral sphincter has been beneficial in spinal cord injury patients with detrusor sphincter dyssynergia [67]. Several small studies have demonstrated improvement [68-70]. Botulinum toxin has also been proposed as a potentially new treatment regimen to improve bladder emptying for children with DV who have failed standard therapy. Petronijevic et al examined the role of combined the injection of botulinum toxin-A (BTX-A) and biofeedback in the management of the female children with DV who were refractory to standard therapy, and analyzed their clinical outcomes. The dose of 500 units of BTX-A was diluted in $2.5 \mathrm{ml}$ saline and injected transperineally around the urethral meatus at the 3, 6, 9 and 12 o'clock positions, 1 to $2 \mathrm{~cm}$ deep into the external urinary sphincter. After treatment the mean voided volume increased while post-void residual urine volume decreased significantly. Significant differences in other uroflowmetry parameters were not found [71]. In another study, Radojicic et al. investigated the results of BTX-A into the urethral sphincter and/or pelvic floor muscle injection combined with behavioural and biofeedback therapy in children with DV resistant to previous treatments, including behavioural, biofeedback and alpha-blockers in 8 boys and 12 girls. The dose of $100 \mathrm{IU}$ BTX-A was diluted in $4 \mathrm{ml}$ saline and injected by a transperineal 21 or 23 gauge needle in the pelvic floor, including the external sphincter. Six months after treatment residual urine decreased significantly in 17 of 20 patients. Nine patients re-established a normal voiding curve and 8 showed improvement. Three did not manifest any significant improvement [72]. The limitations of the studies advocating the use of botulinum toxin are small sample size, lack of standard dosing, and nonrandomization.

Sacral neuromodulation has been successful in children with refractory DV, but the invasiveness of this modality has limited its use in children without neurologic deficits [73]. Its feasibility and efficacy has been well demonstrated [74]. Storage symptoms resolve in about threefourths of children [74]. The response of DV to neuromodulation with the Interstim neuromodulation device was modest. In a single centre study, urinary incontinence, urgency and frequency, nocturnal enuresis and constipation were improved or resolved in $88 \%, 69 \%$, $89 \%, 69 \%$ and $71 \%$ of the patients, respectively [74]. In a multi-institutional study, about $60 \%$ of children with voiding difficulty had some benefit [75]. Neuromodulation offers the additional incentive of a potential improvement in constipation and irritable bowel symptoms [74, 76]. 
Less invasive neuromodulatory devices such as tibial nerve stimulation and transcutaneous electrical nerve stimulation (TENS) have been proposed as treatment modalities. Capitanucci et al. evaluated the efficacy of percutaneous tibial nerve stimulation for different types of paediatric LUTD. A total of 14 children with idiopathic OAB, 14 with DV, 5 with underactive bladder, 4 with underactive valve bladder and 7 with neurogenic bladder resistant to conventional therapy underwent percutaneous tibial nerve stimulation weekly for $30 \mathrm{~min}$ on a weekly schedule for 12 weeks. Patients with DV were significantly more likely to benefit as compared to those with OAB at rates of up to $100 \%$ [77]. TENS has had success in the treatment of $\mathrm{OAB}$ syndrome when compared with placebo in one prospective trial [78]. The use of neuromodulation as treatment modality in refractory LUTD is promising, but larger prospective trials will be necessary to solidify its role as a treatment modality.

\section{Author details}

Yusuf Kibar' ${ }^{1 *}$ and Faysal Gok ${ }^{2}$

*Address all correspondence to: ykibar@gata.edu.tr

1 Gulhane Military Medical Academy, Department of Urology, Section of Paediatric Urology, Ankara, Turkey

2 Gulhane Military Medical Academy, Department of Peadiatrics, Division of Paediatric Nephrology, Ankara, Turkey

\section{References}

[1] Kibar Y. Current Managenement of Urinary Tract Infection in Children. In: Tenke P. (ed.) Urinary Tract Infections. Rijeka: InTech; 2011. p267-284.

[2] Ballek NK, McKenna PH. Lower urinary tract dysfunction in childhood. Urol Clin N Am 2010;37:215-228.

[3] Koff SA, Wagner TT, Jayanthi VR. The relationship among dysfunctional elimination syndromes, primary vesicoureteral reflux and urinary tract infections in children. J Urol 1998;160:1019-1022.

[4] Ellsworth PI, Merguerian PA, Copening ME. Sexual abuse: another causative factor in dysfunctional voiding. J Urol 1995;153:773-776.

[5] Bauer SB, Retik AB, Colodny AH, Hallett M, Khoshbin S, Dyro FM. The unstable bladder of childhood. Urol Clin North Am 1980;7(2):321-336. 
[6] Bauer SB, Yeung CK, Sihoe JD. Voiding dysfunction in children: neurogenic and nonneurogenic. In: Kavoussi LR, Novick AC, Partin AW. (eds.) Campbell's Urology. 9th edition. Philadelphia: WB Saunders Co; 2007. p.3604-55.

[7] Franco I. Overactive bladder in children. Part 1: pathophysiology. J Urol 2007;178(3 Pt 1):761-8.

[8] Feldman AS, Bauer SB. Diagnosis and management of dysfunctional voiding. Curr Opin Pediatr 2006;18:139-147.

[9] Chase J, Austin P, Hoebeke P, McKenna P; International Children's Continence Society. The management of dysfunctional voiding in children: a report from the Standardisation Committee of the International Children's Continence Society. J Urol 2010;183(4):1296-302.

[10] Neveus T, von Gontard A, Hoebeke P, Hjälmas K, Bauer S, Bower W, Jorgensen TM, Rittig S, Walle JV, Yeung CK, Djurhuus JC. The standardization of terminology of lower urinary tract function in children and adolescents: report from the Standardization Committee of the International Children's Continence Society. J Urol 2006;176(1):314-24.

[11] Hoebeke P, Van Laecke E, Van Camp C, Raes A, Van De Walle J. One thousand video-urodynamics studies in children with non-neurogenic bladder sphincter dysfunction. BJU Int 2001;87:575-80.

[12] Ural Z, Ulman I, Avanoglu A. Bladder dynamics and vesicoureteric reflux: factors associated with idiopathic lower urinary tract dysfunction in children. J Urol 2008;179:1564-67.

[13] Bauer SB. Special considerations of the overactive bladder in children. Urology 2002; 60(suppl 5A):43-48.

[14] Koff SA, Solomon MH, Lane GA, Lieding KC. Urodynamic studies in anesthetized children. J Urol 1980;123:61-63.

[15] Bauer SB, Koff SA, Jayanthi VR. Voiding dysfunction in children: neurogenic and non-neurogenic. In: Walsh PC, Retik AB, Vaughn ED, Wein AJ. (eds.) Campbell's Urology. 8th Ed. Philadelphia: WB Saunders Co; 2002. pp.2231-2283.

[16] Bhatia M, Nigam V, Bohra N, Malik S. Attention deficit disorder with hyperactivity among paediatric outpatients. J Child Psychol Psychiatry 1991;32:297-306.

[17] Duel BP, Steinberg-Epstein R, Hill M, Lerner M. A survey of voiding dysfunction in children with attention deficit-hyperactivity disorder. J Urol 2003;170:1521-1524.

[18] Jayanthi VR, Khoury AE, McLorie GA, Churchill BM, Khoury AE. The nonneurogenic neurogenic bladder of early infancy. J Urol 1997;158 (3 Pt 2):1281-5.

[19] Al Mosawi AJ. Identification of nonneurogenic neurogenic bladder in infants. Urology 2007;70(2):355-6. 
[20] Ochoa B. Can a congenital dysfunctional bladder be diagnosed from a smile? The Ochoa syndrome updated. Pediatr Nephrol 2004;19(1):6-12.

[21] Carlson KV, Rome S, Nitti VW. Dysfunctional voiding in adult females. J Urol 2001;165:143-7.

[22] Afshar K, Blake T, Jaffari S, MacNeily AE, Poskitt K, Sargent M. Spinal cord magnetic resonance imaging for investigation of nonneurogenic lower urinary tract dysfunction-can the yield be improved? J Urol 2007;178:1748-50.

[23] Tubbs RS, Oakes WJ. Can the conus medullaris in normal position be tethered? Neurol Res 2004;26:727-31.

[24] Steinbok P, Kariyattil R, MacNeily AE. Comparison of section of filum terminale and non-neurosurgical management for urinary incontinence in patients with normal conus position and possible occult tethered cord syndrome. Neurosurgery 2007;61:550-5.

[25] Ochoa B, Gorlin RJ. Urofacial (ochoa) syndrome. Am J Med Genet 1987;27:661-7.

[26] Parekh DJ, Pope JC IV, Adams MC, Brock JW 3rd. The role of hypercalciuria in a subgroup of dysfunctional voiding syndromes of childhood. J Urol 2000;164:1008-10.

[27] Snodgrass W. The impact of treated dysfunctional voiding on the nonsurgical management of vesicoureteric reflux. J Urol 1998;160:1823-5.

[28] Sjostrom S, Sillen U, Bachelard M, Hansson S, Stockland E. Spontaneous resolution of high grade infantile vesicoureteral reflux. J Urol 2004;172:694-8.

[29] Kibar Y, Ors O, Demir E, Kalman S, Sakallioglu O, Dayanc M. Results of biofeedback treatment on reflux resolution rates in children. Urology 2007;70:563-6.

[30] Winberg J. Progressive renal damage from infection with or without reflux. J Urol 1992;148:1733-4.

[31] Holland N, Jackson E, Kazee M, Conrad GR, Ryo UY. Relation of urinary tract infection and vesicoureteral reflux to scars: follow up in 38 patients. J Pediatr 1990;116(5):S65-71.

[32] Linshaw MA. Asymptomatic bacteriuria and vesicoureteral reflux in children. Kidney Int 1996;50:312-29.

[33] Naseer SR, Steinhardt GF. New renal scars in children with urinary tract infection, vesicoureteral reflux and voiding dysfunction: a prospective evaluation. J Urol 1997;158:566-8.

[34] Acar B, Arıkan FI, Germiyanoglu C, Dallar Y. Influence of high bladder pressure on vesicoureteral reflux and its resolution. Urol Int 2009;82:77-80.

[35] Sillen U. Bladder dysfunction and vesicoureteral reflux. Adv Urol 2008;815472:1-8. 
[36] Soygur T, Arıkan N, Yesilli C, Gogus O. Relationship among pediatric voiding dysfunction and vesicoureteral reflux and renal scars. Urology 1999;54:905-8.

[37] Van Gool JD, Hjalmas K, Tamminen-Mobius T, Olbing H. Historical clues to the complex of dysfunctional voiding, urinary tract infection and vesicoureteral reflux. J Urol 1992; 148(5 Pt 2):1699-1702.

[38] Tilanus M, Klijn A, Dik P, de Kort L, de Jong T. Urodynamic findings and functional or anatomical obstructions in children who developed bladder diverticula after reimplantation of the ureter. Neurourol Urodyn 2009;28:241-5.

[39] Chen JJ, Mao W, Homayoon K, Steinhardt GF. A multivariate analysis of dysfunctional elimination syndrome and its relationships with gender, urinary tract infection and vesicoureteral reflux in children. J Urol 2004;171:1907-10.

[40] Herndon CDA, Decambre M, McKenna PH. Changing concepts concerning the management of vesicoureteral reflux. J Urol 2001;166:1439-43.

[41] Whelan CM, McKenna PH. Dysfunctional voiding as a co-factor of recurrent UTI. Contemp Urol 2004;16:58-73.

[42] Hinman F. Mechanisms for the entry of bacteria and the establishment of urinary infection in female children. J Urol 1966;96(4):546-50.

[43] Chang S, Yang S. Variability, related factors, and normal reference value of post-void residual urine in healthy kindergarteners. J Urol 2009;182:1933-8.

[44] Farhat W, Bägli DJ, Capolicchio G, O’Reilly S, Merguerian PA, Khoury A, McLorie GA. The dysfunctional voiding scoring system: Quantitative standardization of dysfunctional voiding symptoms in children. J Urol 2000;164(3 Pt 2):1011-5.

[45] Upadhyay J, Bolduc S, Bagli DJ, McLorie GA, Khoury AE, Farhat W. Use of the dysfunctional voiding symptom score to predict resolution of vesicoureteral reflux in children with voiding dysfunction. J Urol 2003;169(5):1842-46.

[46] Akbal C, Genc Y, Burgu B, Ozden E, Tekgul S. Dysfunctional voiding and incontinence scoring system: Quantitative evaluation of incontinence symptoms in pediatric population. J Urol 2005;173:969-73.

[47] Afshar K, Mirbagheri A, Scott H, MacNeily AE. Development of a symptom score for dysfunctional elimination syndrome. J Urol 2009;182(4 Suppl):939-43.

[48] Minardi D, Parri G, d'Anzeo G, Fabiani A, El Asmar Z, Muzzonigro G. Perineal ultrasound evaluation of dysfunctional voiding in women with recurrent urinary tract infections. J Urol 2008;179:947-51.

[49] de Jong TP, Klijn AJ, Vijverberg MA, de Kort LM, van Empelen R, Schoenmakers MA. Effect of biofeedback training on paradoxical pelvic floor movement in children with dysfunctional voiding. Urology. 2007;70(4):790-3. 
[50] Chrzan R, Klijn AJ, Vijverberg MA, Sikkel F, de Jong TP. Colonic washout enemas for persistent constipation in children with recurrent urinary tract infections based on dysfunctional voiding. Urology 2008;71:607-10.

[51] Kibar Y, Demir E, Irkilata C, Ors O, Gok F, Dayanc M. Effect of biofeedback treatment on spinning top urethra in children with voiding dysfunction. Urology 2007;70(4):781-4.

[52] Sinha S. Dysfunctional voiding: A review of the terminology, presentation, evaluation and management in children and adults. Indian J Urol 2011;27(4):437-47.

[53] Wiener JS, Scales MT, Hampton J, King LR, Surwit R, Edwards CL. Long term efficacy of simple behavioral therapy for daytime wetting in children. J Urol 2000;164(3 Pt 1):786-90.

[54] Wennergren H, Oberg B, Sandstedt P. The importance of leg support for relaxation of the pelvic floor muscles: a surface electromyography study in healthy girls. Scand J Urol Nephrol 1991;25:205-13.

[55] Silva JM, Diniz JSS, Lima EM, Vergara RM, Oliveira EA. Predictive factors of resolution of primary vesico-ureteric reflux: a multivariate analysis. BJU Int 2006;97(5): 1063-8.

[56] Loening-Baucke V. Urinary incontinence and urinary tract infection and their resolution with treatment of chronic constipation of childhood. Pediatrics 1997;100(2 Pt 1): 228-32.

[57] Yagci S, Kibar Y, Akay O, Kilic S, Erdemir F, Gok F, Dayanc M. The effect of biofeedback treatment on voiding and urodynamic parameters in children with voiding dysfunction. J Urol 2005;174(5):1994-7.

[58] Desantis DJ, Leonard MP, Preston MA, Barrowman NJ, Guerra LA. Effectiveness of biofeedback for dysfunctional elimination syndrome in pediatrics: a systematic review. J Pediatr Urol 2011;7(3):342-8.

[59] Combs AJ, Glassberg AD, Gerdes D, Horowitz M. Biofeedback therapy for children with dysfunctional voiding. Urology 1998;52:312-5.

[60] Kibar Y, Piskin M, Irkilata HC, Aydur E, Gok F, Dayanc M. Management of abnormal postvoid residual urine in children with dysfunctional voiding. Urology 2010;75:1472-5.

[61] Curran MJ, Kaefer M, Peters C, Logigian E, Bauer SB. The overactive bladder in childhood: long-term results with conservative management. J Urol 2000;163:574-7.

[62] Willemsen J, Nijman RJ. Vesicoureteral reflux and videourodynamic studies: results of a prospective study. Urology 2000;55:939-43.

[63] Pohl HG, Bauer SB, Borer JG, Diamond DA, Kelly MD, Grant R, Briscoe CJ, Doonan $\mathrm{G}$, Retik AB. The outcome of voiding dysfunction managed with clean intermittent 
catheterization in neurologically and anatomically normal children. BJU Int 2002;89(9):923-7.

[64] Cain MP, Wu SD, Austin PF, Herndon CD, Rink RC. Alpha blocker therapy for children with dysfunctional voiding and urinary retention. J Urol 2003;170(4 Pt 2):1514-5.

[65] Kramer SA, Rathbun SR, Elkins D, Karnes RJ, Husmann DA. Double blind placebo controlled study of alpha-adrenergic receptor antagonists (doxazosin) for treatment of voiding dysfunction in the pediatric population. J Urol 2005;173(6):2121-4.

[66] Donohoe JM, Combs AJ, Glassberg KI. Primary bladder neck dysfunction in children and adolescents II: results of treatment with alpha-adrenergic antagonists. J Urol 2005;173(1):212-6.

[67] Schurch B, Hauri D, Rodic B, Curt A, Meyer M, Rossier AB. Botulinum-A toxin as a treatment of detrusor-sphincter dyssynergia: a prospective study in 24 spinal cord injury patients. J Urol 1996;155(3):1023-29.

[68] Mokhless I, Gaafar S, Fouda K, Shafik M, Assem A. Botulinum A toxin urethral sphincter injection in children with nonneurogenic neurogenic bladder. J Urol 2006;176(4 Pt 2): 1767-70.

[69] Steinhardt GF, Naseer S, Cruz OA. Botulinum toxin: Novel treatment for dramatic urethral dilatation associated with dysfunctional voiding. J Urol 1997;158(1):190-1.

[70] Franco I, Landau-Dyer L, Isom-Batz G, Collett T, Reda EF. The use of botulinum toxin A injection for the management of external sphincter dyssynergia in neurologically normal children. J Urol 2007;178(4 Pt 2):1775-9.

[71] Petronijevic V, Lazovic M, Vlajkovic M, Slavkovic A, Golubovic E, Miljkovic P. Botulinum toxin type $\mathrm{A}$ in combination with standard urotherapy for children with dysfunctional voiding. J Urol 2007;178(6):2599-602.

[72] Radojicic ZI, Perovic SV, Milic NM. Is it reasonable to treat refractory voiding dysfunction in children with botulinum-A toxin? J Urol 2006;176(1):332-6.

[73] Bower WF, Yeung CK. A review of non-invasive electro neuromodulation as an intervention or non-neurogenic bladder dysfunction in children. Neurourol Urodyn 2004;23:63-7.

[74] Roth TJ, Vandersteen DR, Hollatz P, Inman BA, Reinberg YE. Sacral neuromodulation for the dysfunctional elimination syndrome: A single center experience with 20 children. J Urol 2008;180:306-11.

[75] Humphreys MR, Vandersteen DR, Slezak JM, Hollatz P, Smith CA, Smith JE, Reinberg YE. Preliminary results of sacral neuromodulation in 23 children. J Urol 2006;176(5):2227-31.

[76] Killinger KA, Kangas JR, Wolfert C, Boura JA, Peters KM. Secondary changes in bowel function after successful treatment of voiding symptoms with neuromodulation. Neurourol Urodyn 2011;30:33-7. 
[77] Capitanucci ML, Camanni D, Demelas F, Mosiello G, Zaccara A, De Gennaro M. Longterm efficacy of percutaneous tibial nerve stimulation for different types of lower urinary tract dysfunction in children. J Urol 2009;182(4 Suppl): 2056-61.

[78] Hagstroem S, Mahler B, Madsen B, Djurhuus JC, Rittig S. Transcutaneous electrical nerve stimulation for refractory daytime urinary urge incontinence. J Urol 2009;182(4 Suppl):2072-8. 